\title{
Comprehensive analysis of the retaining pile structure with the determining the stability factor by numerical methods
}

\author{
Olha Dubinchyk ${ }^{1, *}$, Volodymyr Petrenko ${ }^{1}$, Dmytro Ihnatenko ${ }^{1}$, and Vitalii Kildieiev ${ }^{1}$ \\ ${ }^{1}$ Dnipro National University of Railway Transport named after Academician V. Lazaryan, 49010, \\ Dnipro, Lazaryan Str., 2, Ukraine
}

\begin{abstract}
The paper highlights the results of the complex analysis of the retaining pile structure with determining the stability coefficient by numerical methods. To achieve this purpose, after designing a structure with jet grouting piles, the research of the stability coefficients of the landslide hazard slopes in the software complex "OTKOS" and its stress state in the software complex LIRA-CAD system was conducted. The relevance of the completed research is to develop rational parameters of the pile structure. A comparison of determining the stability coefficient of a slope by different methods for the existing landslide stretch for the public roadways of local significance C141017 (Lviv-Shehyni) - Sudova Vyshnia was carried out. Originality of the paper lies in the fact that to determine the stability coefficient in the model, the layeredness of the slope under study is taken into account, and the nonlinear volumetric problem is solved in the course of the numerical analysis of the stress state. The rational distance between piles in the gap and the length of the pile under a certain percentage of cement and ground was justified.
\end{abstract}

\section{Introduction}

The most promising methods for studying the stress state of rock massifs forming slopes are numerical methods that allow significantly expanding the possibilities of mathematical simulation [1-3]. To determine the strength and stability of the slope different modifications of variational-difference methods, finite element methods and the method of boundary elements are used.

The analysis of possibilities of various numerical methods shows that every of them can be used in solving only a certain number of issues and has some accuracy. It was established that the greatest errors in the use of numerical methods occur at points on the contours of the investigated area, which significantly reduces the effectiveness of their application in assessing the strength and stability in the near-surface area [4]. That is why the numerical analysis should be combined with other types of the research, for example, analytical methods and methods of physical simulation (trough research, centrifugal testing of models, etc.) [5].

\footnotetext{
*Corresponding author: alexeytutkin@gmail.com
} 
A reasonable combination of numerical methods and conceptual foundations of analytical methods allows solving the most complicated problems that arise in the research of the stress-strain state of rock massifs, which is an indispensable step in assessing the stability of slopes. Using the capabilities of modern technology, with the help of numerical methods one can determine the strength and stability of inhomogeneous and anisotropic rock massifs with nonuniform and external boundaries having inclusions or cavities dissected by closed or open cracks that take up compression or tension, as well as in cases of three-dimensional problem statement, taking into account plastic deformations that are developing and at man-made disturbance [6, 7].

In the mathematical simulation of the landslide process, the finite element method is fruitfully applied, in which the idealization of the continuous medium consists in replacing it with a system of flat or solid elements that are adjacent to each other and fastened together at the vertices of these elements [8-10].

\section{Methods}

In order to strengthen the slopes of different angles, the construction industry offers a variety of materials and structures. Modern construction technologies provide various ways to reduce the steepness of land, but this is not always advisable. An effective and reliable means of controlling landslides and deformations of slopes is the use of a retaining structure with vertical and inclined jet grouting piles. The schematic construction of the pile retaining wall, which is proposed by the authors, is shown in Figure 1.
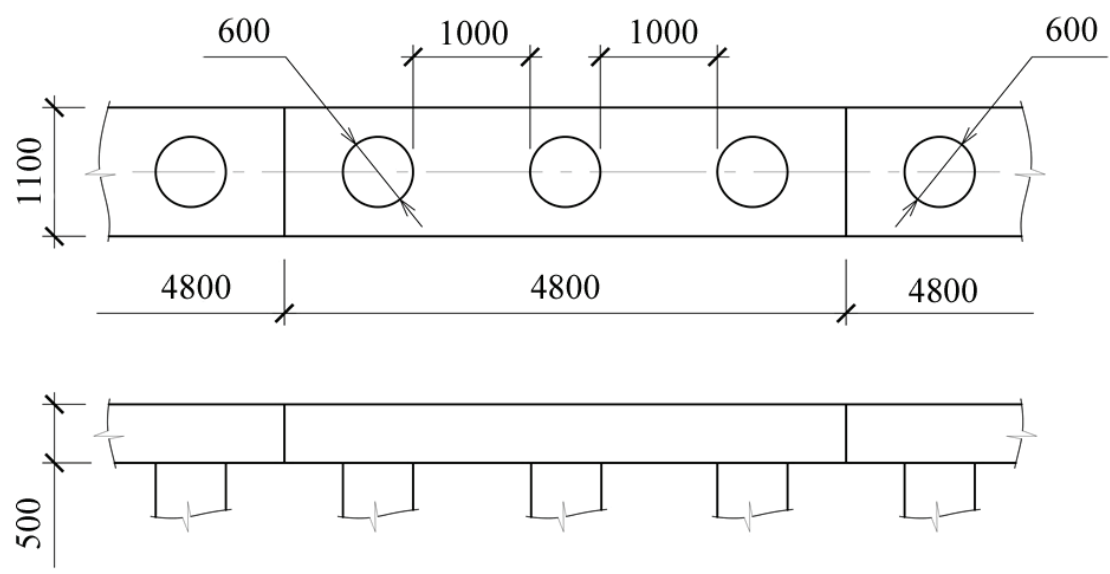

Fig. 1. Schematic construction of the pile retaining wall (fragment).

To substantiate the effectiveness of using the provided pile structure on a landslide hazard slope, a comprehensive analysis of the slope stability at the stretch of public roadways of local significance C141017 (Lviv-Shehyni) - Sudova Vyshnia, km 1+500 $\mathrm{km} \mathrm{2+500} \mathrm{section} \mathrm{was} \mathrm{performed.} \mathrm{The} \mathrm{boundary} \mathrm{of} \mathrm{the} \mathrm{landslide} \mathrm{section} \mathrm{under} \mathrm{the} \mathrm{research}$ in accordance with administrative geography is located in the Mostyska district of the Lviv region. In the geostructural sense, the landslide hazard area is located within the outer zone of Pre-Carpathian foredeep separating the East European platform from the folded region of the Carpathians.

In the geological structure, sediments of the basement, represented by the Neogene age formations, composed of clays with interlayers of dust, micaceous sands. Montmorillonitehydromicaceous, thin-micaceous, viscous clays, from solid to low-plasticity ones, with interlayers of aleuritic sand, sometimes very ferruginous. Layers of sand reduce the 
adhesion value in $2 \ldots 4$ times. Thin layering, the presence of water bearing layers of aleurite and sand contributes to the development of landslide deformations in clays and complicates their use as bases. Dust sand, the filtration coefficient is $0.3 \ldots 0.5 \mathrm{~m} /$ day.

The calculation was divided into two stages. At the first stage, the stability coefficients $C_{l s}$ of the slope were determined by different methods in the software complex "OTKOS" (license number F755B84 (KMBKB RA 4810)). In normative documents it is shown that the value of the stability coefficients $C_{l s}$ is the main characteristic of the stability of the slope. In general, the stability coefficient $C_{l s}$ equals the ratio of holding $\sum T_{i}$ and shifting $\sum N_{i}$ forces:

$$
C_{l s}=\frac{\sum T_{i}}{\sum N_{i}} .
$$

The methods for determining the stability coefficient $C_{l s}$, which satisfy the general equilibrium of the moments, include the Simplified Bishop method, which satisfies the requirements of vertical forces (the balance of the forces of displacement is preserved). It is recommended to perform most of the practical calculations, the equation for calculating $C_{l s}$ using the simplified Bishop method is as follows:

$$
C_{l s}=\frac{\sum\left[(C \beta+W \tan \varphi)\left(\cos \alpha+\frac{\sin \alpha \cdot \tan \alpha}{C_{l s}}\right)\right]}{\sum W \sin \alpha},
$$

where $C$ - cohesion, MPa; $\varphi$ - angle of internal friction, deg; $W$ - mass of the compartment, $\mathrm{t} ; \beta$ - length of the sliding surface of the compartment, $\mathrm{m} ; \alpha$ - angle of inclination of the sliding plane of the compartment, deg.

Since the stability coefficient $C_{l s}$ is included in the left and right sides of the equation, for its solution it is necessary to introduce assumptions about its initial value. Further, the solution of the equation is reduced to an iterative process, which ends when $C_{l s}$ yielded is not less than the given permissible error.

The type of methods that satisfy the general equilibrium of forces include the Janbu Corrected Method and the Lowe-Karafiath Method, the equation for which is the following:

$$
K_{3 c}=\frac{\sum(C l+(P-u l) \tan \varphi)}{\sum W \sin \alpha},
$$

where $C$ - cohesion, MPa; $l$ - length of the sliding line, $\mathrm{m} ; P$ - friction force, $\mathrm{kN}$; $u$ - porous pressure, $\mathrm{MPa} ; \varphi$ - angle of internal friction, deg; $W$ - mass of the compartment, $\mathrm{t} ; \alpha$ - angle of inclination of the sliding plane of the compartment, deg.

The Bishop and Lowe-Karafiath Method methods provide the limit values of $C_{l s}$, respectively, overestimated and understated, which allows us to estimate the boundaries of the safety factor. After determining the most dangerous variant of the landslide development, the analysis was reduced to calculating the bearing capacity of the pile structure, which interacts with the moving ground massif. The method of calculating the parameters of jet grouting piles for the engineering protection of the landslide hazard slopes involves finite element simulation and calculation of the nonlinear volumetric problem in the software complex LIRA-CAD system (license number \#1d/2063). 


\section{Results and discussion}

After the model creation in the software complex "OTKOS" it was completed its full calculation. The results of calculating the slope stability by different methods are presented in Figures 2-7.

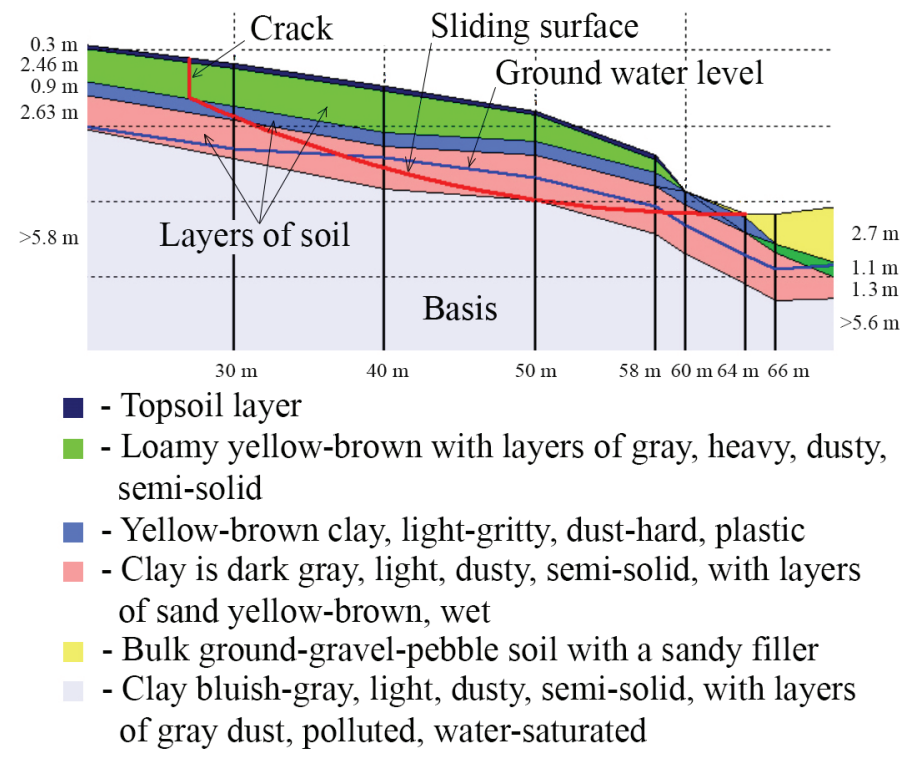

Fig. 2. Results of calculating the slope stability using the Bishop method (simplified), $C_{l s}=1.449$.

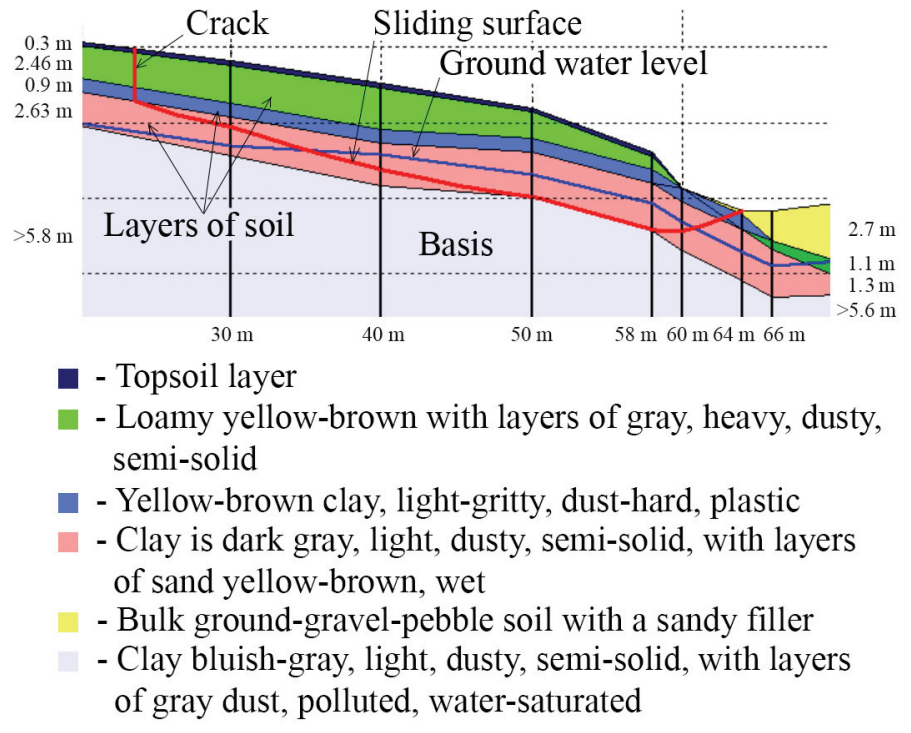

Fig. 3. Results of calculating the slope stability by Corps of Engineers method \#1, $C_{l s}=1.203$. 


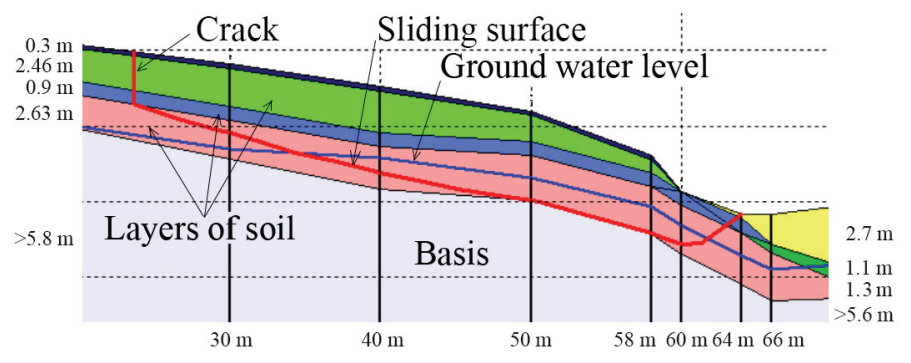

- Topsoil layer

- Loamy yellow-brown with layers of gray, heavy, dusty, semi-solid

- Yellow-brown clay, light-gritty, dust-hard, plastic

- Clay is dark gray, light, dusty, semi-solid, with layers of sand yellow-brown, wet

- Bulk ground-gravel-pebble soil with a sandy filler

- Clay bluish-gray, light, dusty, semi-solid, with layers of gray dust, polluted, water-saturated

Fig. 4. Results of calculating the slope stability by Lowe-Karafiath method, $C_{l s}=1.134$.

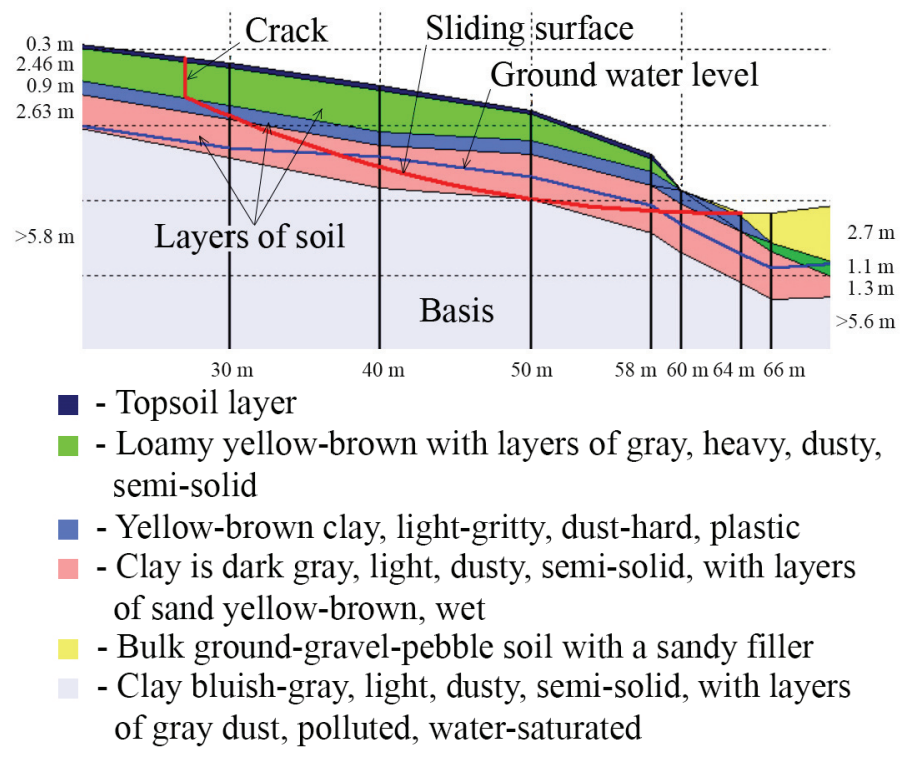

Fig. 5. Results of calculating the slope stability by Spenser method, $C_{l s}=1.452$. 


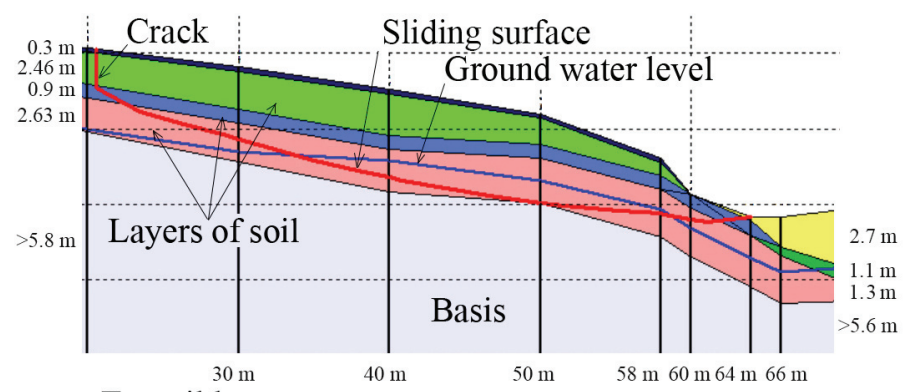

- Topsoil layer

- Loamy yellow-brown with layers of gray, heavy, dusty, semi-solid

- Yellow-brown clay, light-gritty, dust-hard, plastic

- Clay is dark gray, light, dusty, semi-solid, with layers of sand yellow-brown, wet

- Bulk ground-gravel-pebble soil with a sandy filler

- Clay bluish-gray, light, dusty, semi-solid, with layers of gray dust, polluted, water-saturated

Fig. 6. Results of calculating the slope stability by the Fedorovskyi-Kurylo method, $C_{l s}=1.369$.

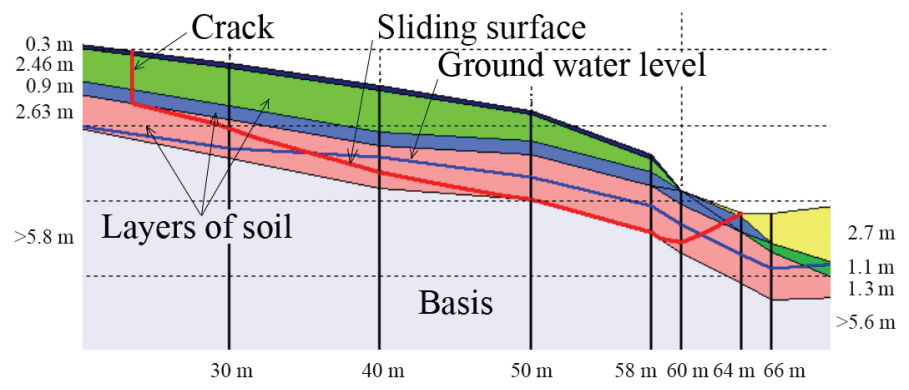

- Topsoil layer

- Loamy yellow-brown with layers of gray, heavy, dusty, semi-solid

- Yellow-brown clay, light-gritty, dust-hard, plastic

- Clay is dark gray, light, dusty, semi-solid, with layers of sand yellow-brown, wet

- Bulk ground-gravel-pebble soil with a sandy filler

- Clay bluish-gray, light, dusty, semi-solid, with layers of gray dust, polluted, water-saturated

Fig. 7. Results of calculating the slope stability using the Janbu method (corrected), $C_{l s}=1.193$.

After analysis, one can conclude that the worst scenario of the developing the landslide occurs in the case when on the basis of the calculation the stability factor is minimal, that is, by the Lowe-Karafiath method, $C_{l s}=1.134$ (Fig. 4). When choosing the rational parameters of the pile structure, the slope stability and the efficiency of the construction were taken into account. Several variants of the pile structure are considered and its parameters (length and diameter of piles, step between them and physical-mechanical properties of the piles material affecting the modulus of deformation and specific weight) were indicated. 
The software complex "LIRA-CAD system-2017" allows calculating the nonlinear problem of geomechanics using special finite elements (CE) that simulate the ground operation. Layers of the ground were simulated by volumetric elements, type CE 271-276 with the corresponding physical-mechanical characteristics that were obtained as a result of geotechnical surveys. CE-10 jet grouting piles were represented by universal spatial bar CE. According to the software complex "LIRA-CAD system 2017", it was assumed that CE 271 are physical nonlinear volumetric $\mathrm{CE}$ of the ground in the form of a parallelepiped, and CE 276 are physical nonlinear volumetric 8-nodal CE of the ground (arbitrary hexahedra). Calculation results (deformed state) are shown in Figures 8-9.

\begin{tabular}{cccccc}
\hline-0.135 & -0.113 & -0.0564 & -0.00135 & 0.00135 \\
\hline \hline 0.0564 & 0.113 & 0.169 & 0.226 & \\
\hline \hline 0.226 & 0.282 & 0.339 & 0.395 & 0.452
\end{tabular}

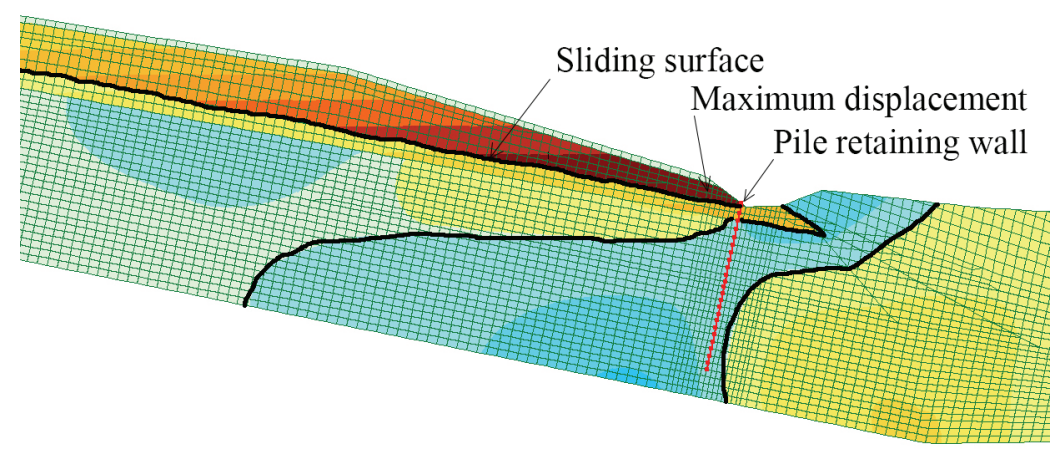

Fig. 8. Horizontal displacements of the slope jointly with the pile structure (maximum displacement is $0.045 \mathrm{~cm})$.

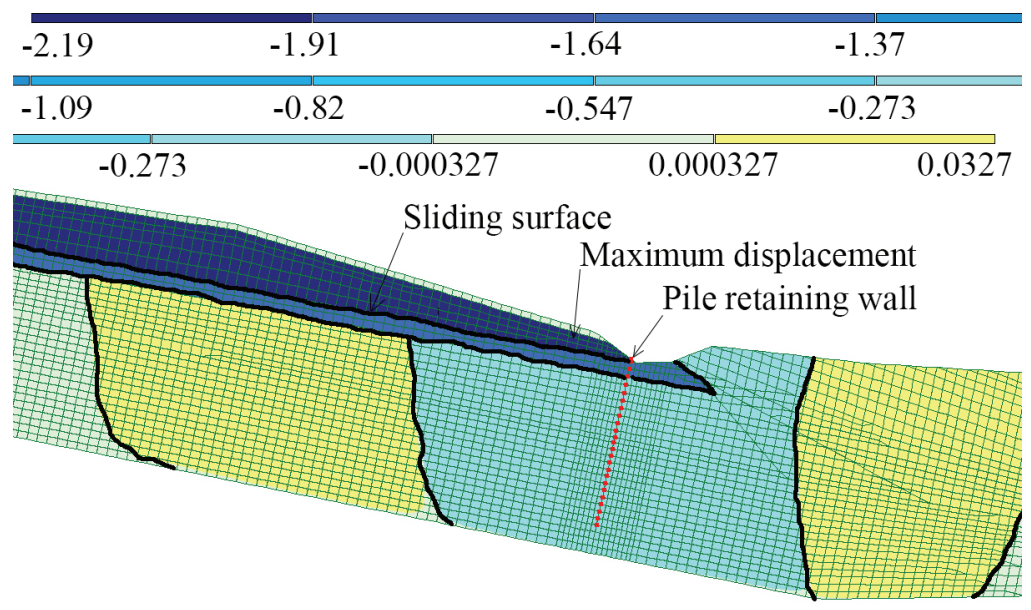

Fig. 9. Vertical displacements of the slope jointly with the pile structure (maximum displacement is $0.31 \mathrm{~cm}$ ).

\section{Conclusions}

On the basis of the performed calculations, a new design of the retaining pile structure for the protection against landslide at the stretch of public roadways of local significance 
C141017 (Lviv-Shehyni) - Sudova Vyshnia, km 1+500 - km 2+500 section with complex engineering-geological and terrain conditions in the Carpathian region.

As determined on the basis of calculations, piles of $0.6 \mathrm{~m}$ in diameter are made from soil cement, composition in percentage terms of $35.5 \%$ and $64.5 \%$ (100 liters of cement grout per 180 liters of ground respectively). The rational distance between the piles in the gap according to the calculation is $1.0 \mathrm{~m}$, and the length of the pile is $8.3 \mathrm{~m}$.

It should be noted that accepting the construction of small foundation frames also increases the stiffness of the retaining pile structure. Recommendations concerning the parameters of foundation frame, which combines three piles: the length between the axes is $3.2 \mathrm{~m}$, the width is $0.6 \mathrm{~m}$, height is $0.5 \mathrm{~m}$. Foundation frame material: reinforced concrete, concrete class - B15, reinforcement class - AI. The joints of piles and foundation frames are provided by overlapping of reinforced bars from piles for an anchor length of $1.0 \mathrm{~m}$.

\section{References}

1. Fedorovskiy, V.G. (1997). Metod rascheta ustoychivosti otkosov i sklonov. Geoekologiya, 6, 95-106

2. A. Fahimifar, A. Atyah, IJCIET, 8, 7 (2017)

3. N. Albataineh, Slope stability analysis using $2 D$ and $3 D$ methods (The university of Akron, Ohio, United States, 2006)

4. Ginzburg, L.K. (2007). Protivoopolznevyye sooruzheniya. Dnepropetrovsk: Lira LTD

5. D. Ignatenko, O.L. Tiutkin, V.D. Petrenko, A.M. Alkhdour IJCIET, 10, 01 (2019)

6. Perelmuter, A.V., Slivker, V.I. (2002). Raschetnyye modeli sooruzheniy $i$ vozmozhnost $i k h$ analiza. Kyiv: Stal

7. Levchenko, S.O. (2012). Sravnitelnyy analiz ispolzovaniya programm PLAXIS i OTKOS pri otsenke ustoychivosti opolznevogo sklona s uchetom seysmicheskikh vozdeystviy, Budivelni konstruktsii, 76, 601-606

8. Petrenko, V.D., Tiutkin, O.L., Dubinchyk, O.I., Kildieiev, V.R. (2015). Otsinka stiikosti pryrodnykh skhyliv metodamy matematychnoho modeliuvannia v prohrami "OTKOS", Mosty ta tuneli: teoriia, doslidzhennia, praktyka, 8, 23-32

9. Petrenko, V.D., Tiutkin, O.L., Ihnatenko, D.Yu., Kovalchuk, V.V. (2018). Comparative calculation of the stability of the landslide slope in the software complexes "OTKOS" and "LIRA-CAD 2017", Mosty ta tuneli: teoriia, doslidzhennia, praktyka, 14, 101-109

10. Tiutkin, O.L., Dubinchyk, O.I., Kildieiev, V.R. (2018). Analiz rezultativ stiikosti porodnykh skhyliv, skladenykh neodnoridnymy ta sharuvatymy gruntamy, Mosty ta tuneli: teoriia, doslidzhennia, praktyka, 14, 81-92 